\title{
Structural equation modeling: an application of broadband penetration and GDP growth in Asia
}

\author{
Tasneem Fatima Alam ${ }^{1}$, Nayeem Sultana ${ }^{2}$ and Md. Israt Rayhan ${ }^{1 *}$
}

*Correspondence:
israt@isrt.ac.bd
${ }^{1}$ Institute of Statistical
Research and Training
(ISRT), University of Dhaka,
Dhaka 1000, Bangladesh
Full list of author information
is available at the end of the
article

*Correspondence: israt@isrt.ac.bd

Institute of Statistical Research and Training Dhaka 1000, Bangladesh Full list of author information article

\begin{abstract}
In the present era of globalization, broadband penetration which indicates access to high-speed internet has allowed the transferring of information in a way that was never observed before. With the growing world-wide investment and attention received by broadband infrastructure, this study examines the relationship between broadband penetration and economic growth with a panel data consisting of ten Asian countries over 2001-2015. This study uses a structural equation modeling approach to estimate the relationship between endogenous broadband penetration and economic growth through two-stage least squares, three-stage generalized method of moments and full-information maximum likelihood estimation. A positive and significant impact of broadband penetration on economic growth is found controlling individual effect of countries.
\end{abstract}

Keywords: Broadband, GDP growth, Structural modeling, 3SLS, FIML

\section{Introduction}

Over the last decade, information and communication technologies (ICT) have grown into a pivotal part of our society. It has secured itself as a very powerful platform that has drastically changed the people's way of life. With the rapid development in ICT and telecommunications area, the internet users continue to grow around the world. It has been reported that $49.7 \%$ of the world population is using the internet (World Internet Users and 2017 Population Stats). About 42\% of the population in Asia Pacific region uses the internet. Most of the countries in South Asia have been experiencing a positive economic boost over the course of past few years, consolidating its position as the fastest growing region in last few years World Bank (2017).

Several empirical investigations exist in the literature which examines how telecommunications infrastructure affects economic growth in developed economies (Röller and Waverman 2001) and in developing economies (Sridhar and Sridhar 2007), assuming a two-way causal link between them. However, this relationship has not been studied in the context of South Asia. Although the share of this region's global consumption of ICT goods is gradually increasing over time, its share in global production has been relatively lower. South Asia comprises eight countries: Afghanistan, Bangladesh, Bhutan, India, Maldives, Nepal, Pakistan and Sri Lanka. Due to the unavailability of data 
on Afghanistan, Pakistan and Nepalare excluded from this study, a panel data including five more Asian countries outside South Asia: China, Iran, Indonesia, Thailand and Turkey, are also considered here according to the uppermost GDP rank. Data are taken over 15 years from 2001 to 2015 for a panel study with simultaneous equations approach to investigate the two-way causal relationship between broadband and economic growth.

The effect of fixed broadband penetration on Latin American economic growth is investigated by Alderete (2017) through implementing a simultaneous equations approach using panel data consisting of Latin American countries for 2010-2014 and found the important contribution of broadband penetration on economic growth. Haller and Lyons (2015) investigated how adoption of broadband service could affect the firm productivity and growth considering different speeds of the service. Prieger (2013) compared the internet speed and broadband usage of rural and urban areas in the USA. The study illustrated a disparity of broadband usage between rural and urban households with low-income areas. Lee et al. (2012) looked into the effect of mobile cellular phones on the GDP growth applying GMM estimator and revealed that the technology mobile cellular phone is an important catalyst of the rate of economic growth in Sub-Saharan Africa. Koutroumpis (2009) investigated the effect of broadband penetration on economy using simultaneous approach in twenty-two European countries using 2SLS IV estimation and 3SLS GMM method and claimed that broadband telecommunications lead to economic growth.

To investigate the relationship between telecommunications and the economic growth in developing countries, this study addresses the following questions: (1) Is economic growth accelerated by broadband service, (2) Does the overall economic growth create more demand for broadband service?

\section{Data and methodology}

A panel data from ten Asian countries are used in this study to model the relationship between broadband investment and economic output. Gross domestic product (GDP) of the countries has been considered as the economic growth indicator. The dataset consists of annual data for a 15-year period 2001-2015 with 2015 as the base year. According to the availability of panel data, five South Asian and five Asian countries from top ranked GDP growth are taken as follows: Bangladesh, Bhutan, India, Maldives, Sri Lanka, China, Iran, Indonesia, Thailand and Turkey from World Development Indicators (WDI). However, Japan, South Korea and Saudi Arabia were excluded due to unavailability of data. Table 1 contains the variables used in the model. The subscripts $i$ and $t$ correspond to country and time values, respectively.

The relationship between broadband infrastructure and the national output of economies is investigated. However, as a growing economy may lead to development in broadband infrastructure and services, the increase in the demand of broadband services may in return be a determinant of economic growth of a nation. Therefore, there exists a possible two-way causal relationship between these two variables. In order to measure this link, a simultaneous equation model is used, where the macro-production equation is jointly estimated with micro-models of supply and demand, thus incorporating the endogeneity effect of telecommunications investment and broadband penetration. These equations are estimated in several methods: two-stage least squares (2SLS), three-stage least squares 
Table 1 List of variables used in the model and description

\begin{tabular}{ll}
\hline Variables & Description \\
\hline $\mathrm{GDP}_{i t}$ & GDP (current US\$) \\
$\mathrm{GDPC}_{i t}$ & GDP per capita (current US\$) \\
$\mathrm{GR}_{i t}$ & GDP growth (annual \%) \\
$\mathrm{FDI}_{i t}$ & Foreign direct investment, net inflows (current US\$) \\
$\mathrm{PEN}_{i t}$ & Fixed broadband subscriptions (per 100 people) \\
$\mathrm{URB}_{i t}$ & Urban population (total) \\
$\mathrm{EDU}_{i t}$ & Enrollment in secondary education \\
$\mathrm{LF}_{i t}$ & Labor force (total) \\
$\mathrm{BBI}_{i t}$ & Investment in telecoms with private participation (current US\$) \\
$\mathrm{MOB}_{i t}$ & Mobile cellular subscriptions (per 100 people) \\
$\mathrm{TAX}_{i t}$ & Total tax rate (\% commercial profits) \\
\hline
\end{tabular}

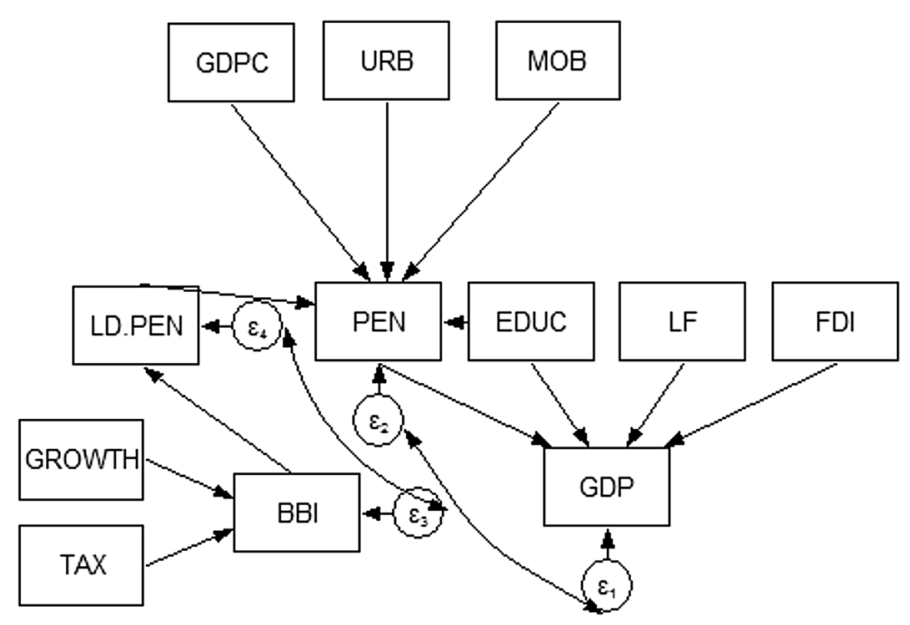

Fig. 1 Structure of the system of equations

(3SLS), generalized method of moment (GMM) estimation and maximum likelihood estimation. The simultaneous equations model used by Röller and Waverman (2001) has been adapted to build the system of equations. In aggregate production function, the national gross economic output (GDP) is related to the foreign direct investment (FDI), total labor force (LF), people receiving general secondary education program (EDUC) and broadband demand infrastructure penetration (PEN). Each of these variables is linked to productivity, which is supported by a large amount of the literature. In order to disentangle the two-way causal link between broadband and GDP, the micro-models of demand, supply and production of broadband infrastructure are introduced. In the demand equation, broadband penetration is related to GDP per capita, urban population, people receiving secondary education of any age and mobile penetration. The supply equation states that investment in telecommunications with private participation is a function of GDP growth and total tax rate calculated as percentage of commercial profit. The infrastructure equation links the annual change in broadband penetration with investment in telecom sector during one year. As the variables are nonlinearly related and the disturbances may not be normally distributed, log-transformation of each variable is taken to construct linear regression models. Thus, the system of equations is depicted in Fig. 1. 


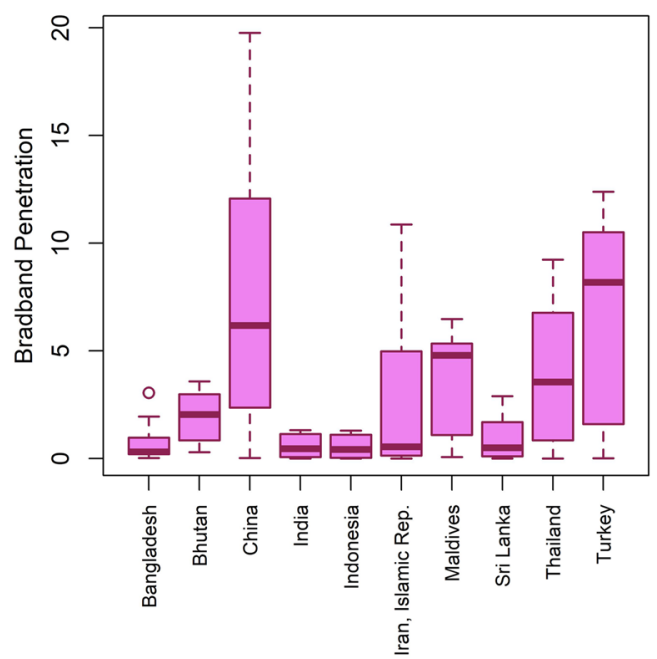

Fig. 2 Boxplot showing broadband penetration by countries

The structural model used in this study is:

$$
\begin{aligned}
& \log \left(\mathrm{GDP}_{i t}\right)=\alpha_{0}+\alpha_{1} \log \left(\mathrm{PEN}_{i t}\right)+\alpha_{2} \log \left(\mathrm{EDUC}_{i t}\right)+\alpha_{3} \log \left(\mathrm{LF}_{i t}\right)+\alpha_{4} \log \left(\mathrm{FDI}_{i t}\right)+\epsilon_{1 i t} \\
& \log \left(\mathrm{PEN}_{i t}\right)=\beta_{0}+\beta_{1} \log \left(\mathrm{GDPC}_{i t}\right)+\beta_{2} \log \left(\mathrm{URB}_{i t}\right)+\beta_{3} \log \left(\mathrm{EDUC}_{i t}\right)+\beta_{4} \log \left(\mathrm{MOB}_{i t}\right)+\epsilon_{2 i t} \\
& \log \left(\mathrm{BBI}_{i t}\right)=\gamma_{0}+\gamma_{1} \log \left(\mathrm{GR}_{i t}\right)+\gamma_{2} \log \left(\mathrm{TAX}_{i t}\right)+\epsilon_{3 i t} \\
& \log \left(\frac{\mathrm{PEN}_{i t}}{\mathrm{PEN}_{i, t-1}}\right)=\delta_{0}+\delta_{1} \log \left(\mathrm{BBI}_{i t}\right)+\epsilon_{4 i t}
\end{aligned}
$$

The structural equations are identified in this study using the rank condition (Gujarati 2009) which is both a necessary and sufficient condition for identification. The fixed and random effect estimators (Baltagi 2008) have been used to estimate the coefficients in the equations.

\section{Analyses and results}

Figure 2 shows boxplots which compare the variability in broadband penetration for each country.

The boxplot exhibits the dispersion in broadband use in different countries. Each boxplot represents the summary of broadband penetration for individual countries, displaying the variation over the study period. This variation is the highest for China, showing a rapid increase in broadband use relative to other countries. The range is also large for countries like Turkey, Iran, Thailand and Maldives. Figure 3 shows a radar chart of broadband penetration, mobile penetration, urbanization and GDP per capita for different countries in 2015.

The chart shows that although broadband penetration is the highest in China in 2015, Maldives has the highest mobile penetration, which may have an effect on its having the highest broadband subscriptions in South Asia. As the world's most populated country, China has the highest urban population, while Turkey possesses the highest GDP per capita among other countries. 


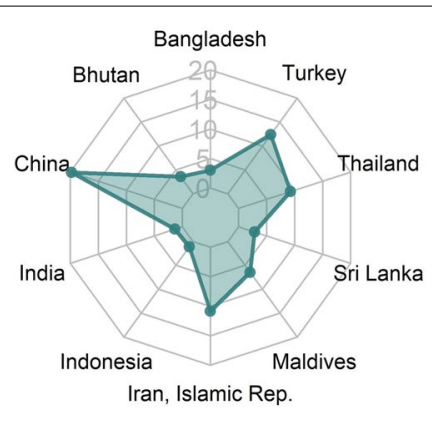

a Broadband Penetration

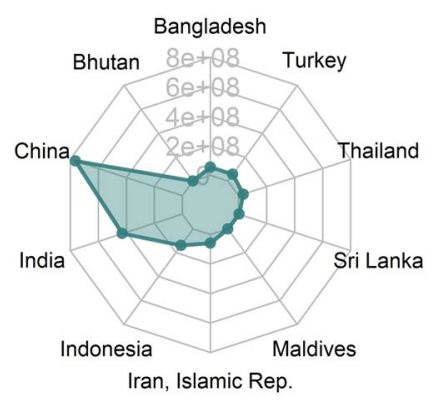

c Urbanization

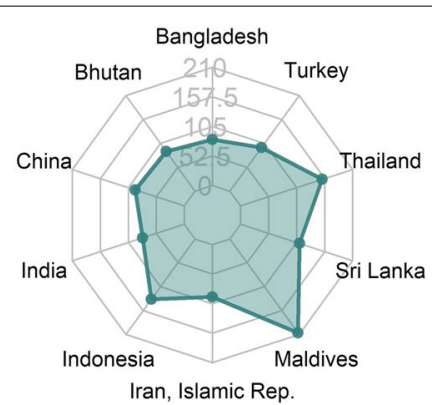

b Mobile Penetration

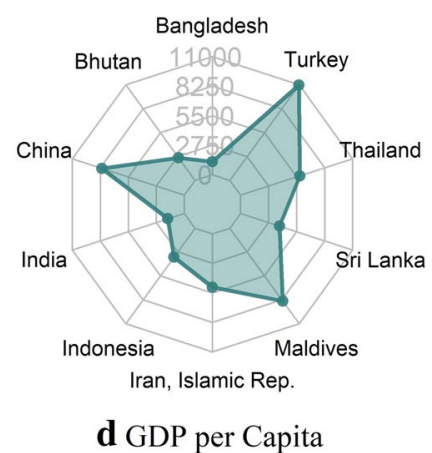

Fig. 3 Radar chart of variables by countries in 2015

Table 2 Endogeneity test by Hausman proposed method

\begin{tabular}{lcc}
\hline Variable & $\boldsymbol{x}^{\mathbf{2}}$ & $\boldsymbol{p}$ value \\
\hline Broadband penetration & 26.350 & 0.000 \\
GDP per capita & 1.111 & 0.292 \\
GDP growth & 0.752 & 0.386 \\
Investment & 3.931 & 0.047 \\
\hline
\end{tabular}

This study has performed the post-estimation test for consistent and efficient parameter estimates. Endogeneity causes inconsistency of the usual OLS estimates and requires instrumental variable (IV) methods like two-stage least squares (2SLS) to obtain consistent parameter estimates (Baltagi 2008). Under the null hypothesis that the specified endogenous regressors can actually be treated as exogenous, the results of the Hausman test for endogeneity (Wooldridge 2010) in the system are presented in the following table.

Table 2 indicates that broadband penetration and telecommunication investment are endogenous ( $p$ values are below $1 \%$ and 5\% level of significance, respectively).

Using the rank condition (Gujarati 2009), it has been found that every equation in the structural model is over-identified. Table 3 presents the results of the singleequation estimates of the production and demand equation by pooled, fixed effect and random effect estimation. In the production equation, all of the three estimates of coefficients of broadband penetration provide significant and positive output. The pooled regression generates the highest positive output which indicates that an 
Table 3 Estimates of pooled, fixed effect and random effect 2SLS regressions (production and demand equation)

\begin{tabular}{llll}
\hline Variables & Pooled regression & Fixed effects & Random effects \\
\hline GDP & & & \\
Broadband penetration & $0.351^{* * *}$ & $0.279^{* *}$ & $0.277^{* * *}$ \\
Labor force & $(0.051)$ & $(0.030)$ & $(0.027)$ \\
Education & -0.117 & 0.329 & $0.619^{* * *}$ \\
& $(0.129)$ & $(0.426)$ & $(0.15)$ \\
FDI & $0.880^{* * *}$ & 0.135 & $0.238^{*}$ \\
& $(0.19)$ & $(0.147)$ & $(0.139)$ \\
Constant & $0.250^{* * *}$ & $0.093^{* *}$ & $0.010^{* *}$ \\
& $(0.061)$ & $(0.044)$ & $(0.045)$ \\
$R^{2}$ & $8.807^{* * *}$ & $7.517^{* * *}$ & $9.398^{* * *}$ \\
Penetration & $(0.502)$ & $(0.862)$ & $(0.945)$ \\
GDPC & 0.981 & 0.724 & 0.963 \\
Urbanization & & & \\
Education & $0.833^{* * *}$ & $1.611^{* * *}$ & $1.357^{* * *}$ \\
& $(0.182)$ & $(0.40)$ & $(0.306)$ \\
Mobile subscriptions & 0.009 & $1.704^{*}$ & 0.379 \\
Constant & $(0.215)$ & $(1.011)$ & $(0.397)$ \\
$R^{2}$ & 0.142 & -0.459 & -0.242 \\
\hline & $(0.236)$ & $(0.524)$ & $(0.419)$ \\
& $1.438^{* * *}$ & $0.999^{* * *}$ & $1.217^{* * *}$ \\
& $(0.12)$ & $(0.17)$ & $(0.145)$ \\
& $-14.73^{* * *}$ & $-12.58^{* * *}$ & $-18.323^{* * *}$ \\
& $(1.395)$ & $(2.841)$ & $(2.613)$ \\
& 0.818 & 0.584 & 0.795 \\
\hline
\end{tabular}

All variables are in log form

***1\% significance level; ${ }^{*} 5 \%$ significance level; ${ }^{*} 10 \%$ significance level. Standard errors are in brackets

increase in broadband penetration has a positive impact on GDP growth. The standard error obtained from this estimate is also the smallest among the three estimates. Although labor force appears positive and significant in the fixed and random effect estimates, it does not appear in the pooled estimate. Again, education appears positive and significant in the pooled regression, while does not appear significant in the fixed and random effect estimates. FDI provides positive and significant estimates in the pooled and random estimates, but generates negative and insignificant estimate in the random effect model. It is notable that pooled, fixed effect and random effect regressions provide a high $R^{2}$ which may be due to the autocorrelation present in the model over time.

Table 4 shows the reverse effect of economic growth on broadband penetration. The outputs from demand function show that GDP per capita has a positive and significant effect on broadband penetration, validating the assumption of the reverse impact of economic growth on penetration. Nevertheless, education appears to be insignificant in all the estimates. Mobile penetration has a significant effect on broadband, which strongly justifies the inter-relationships of the technological development. In the supply equation, GDP growth appears to be insignificant in all the estimates. Again, the effect of tax rate does not provide significant output when controlling for heterogeneity or individual effects, which indicates a poor fitted model for supply equation. The last equation provides insignificant output with an $R^{2}$ of only 0.016 
Table 4 Estimates of pooled, fixed effect and random effect 2SLS regressions (supply and infrastructure production equation)

\begin{tabular}{llll}
\hline Variables & Pooled regression & Fixed effects & Random effects \\
\hline Investment & & & -0.68 \\
Growth & -0.354 & -0.063 & $(0.111)$ \\
Tax & $(0.338)$ & $(0.107)$ & -0.23 \\
Constant & $1.186^{* *}$ & -0.336 & $(0.245)$ \\
& $(0.465)$ & $(0.276)$ & $20.26^{* * *}$ \\
$R^{2}$ & $14.18^{* * *}$ & $21.346^{* * *}$ & $(1.235)$ \\
$\Delta$ penetration & $(1.784)$ & $(1.09)$ & 0.081 \\
Investment & 0.305 & 0.095 & \\
& & & 0.023 \\
Constant & 0.023 & $0.689^{*}$ & $(0.031)$ \\
$R^{2}$ & $(0.031)$ & $(0.313)$ & -0.155 \\
\hline Alvaiabs & -0.112 & -0.217 & $(0.636)$ \\
\end{tabular}

All variables are in log form

***1\% significance level; ${ }^{*} 5 \%$ significance level; ${ }^{*} 10 \%$ significance level. Standard errors are in brackets

implying only $1.6 \%$ variability captured by the random and fixed effect model. Only the estimate for fixed effect model for telecommunications investment appears significant at $10 \%$ level. However, the pooled and the random effect models provide similar estimates indicating no difference between these models. It can be noted that both the supply and the infrastructure production equation include the variable telecommunications investment, which has the highest missing values in the dataset. Due to loss of information, these two equations may provide insignificant outputs and a low $R^{2}$ for both the equations.

In the system of equations of this study, the error terms in one equation are likely correlated with the error terms in the other equations in the system, in which case the 3SLS method may be more appropriate (Wooldridge 2010). However, under assumptions of system instrumental variables (SIV) estimation the GMM 3SLS estimator is consistent while the traditional 3SLS estimator is not. Again, under the assumption of the conditional normality of the dependent variable, given the independent variable, the maximum likelihood method gives more efficient estimates than GMM. When the MLE takes into account the missing values in the dataset, it is known as full-information maximum likelihood (FIML) method. As our dataset contains some missing values, we were interested to observe the performance of the FIML method as well. Again, this method does not consider the heterogeneity or country-specific effects of the panel data similar to the GMM and 3SLS method. The three methods of 3SLS, GMM and MLE are all applicable under the above-mentioned different situations, and hence we compare these three models simultaneously in this study to compare their efficiency through the results.

Table 5 contains outputs of 3SLS and GMM estimation for the production equations and demand equation. The production function shows that broadband penetration has a significant effect on GDP growth, which coincides with results obtained in the single-equation IV estimates. Here, for both 3SLS and GMM methods, for 1\% 
Table 5 3SLS GMM, 3SLS regression and MLE method (production and demand equations)

\begin{tabular}{|c|c|c|c|}
\hline Variables & $\begin{array}{l}\text { 3SLS } \\
\text { Coefficients } \\
\text { and standard error }\end{array}$ & $\begin{array}{l}\text { 3SLS GMM } \\
\text { Coefficients } \\
\text { and standard error }\end{array}$ & $\begin{array}{l}\text { MLE } \\
\text { Coefficients } \\
\text { and standard } \\
\text { error }\end{array}$ \\
\hline \multicolumn{4}{|l|}{ GDP } \\
\hline Broadband penetration & $\begin{array}{l}0.458^{* * *} \\
(0.059)\end{array}$ & $\begin{array}{l}0.458^{* * *} \\
(0.056)\end{array}$ & $\begin{array}{l}0.115^{* * *} \\
(0.022)\end{array}$ \\
\hline Education & $\begin{array}{l}0.669^{* * *} \\
(0.114)\end{array}$ & $\begin{array}{l}0.669^{* * *} \\
(0.085)\end{array}$ & $\begin{array}{l}0.673^{* * *} \\
(0.097)\end{array}$ \\
\hline Labor force & $\begin{array}{l}0.148 \\
(0.131)\end{array}$ & $\begin{array}{l}0.148^{*} \\
(0.09)\end{array}$ & $\begin{array}{l}-0.045 \\
(0.099)\end{array}$ \\
\hline $\mathrm{FDI}$ & $\begin{array}{l}0.172^{* * *} \\
(0.062)\end{array}$ & $\begin{array}{l}0.172^{* * *} \\
(0.055)\end{array}$ & $\begin{array}{l}0.356^{* * *} \\
(0.039)\end{array}$ \\
\hline Constant & $\begin{array}{l}9.287^{* * *} \\
(0.698)\end{array}$ & $\begin{array}{l}9.287^{* * *} \\
(0.556)\end{array}$ & $\begin{array}{l}8.548^{* * *} \\
(0.385)\end{array}$ \\
\hline \multicolumn{4}{|l|}{ Penetration } \\
\hline GDPC & $\begin{array}{l}1.373^{* * *} \\
(0.128)\end{array}$ & $\begin{array}{l}1.373^{* * *} \\
(0.112)\end{array}$ & $\begin{array}{l}0.766^{* * *} \\
(0.173)\end{array}$ \\
\hline Urbanization & $\begin{array}{l}0.034 \\
(0.137)\end{array}$ & $\begin{array}{l}0.034 \\
(0.106)\end{array}$ & $\begin{array}{l}0.122 \\
(0.218)\end{array}$ \\
\hline Education & $\begin{array}{l}0.014 \\
(0.159)\end{array}$ & $\begin{array}{l}0.014 \\
(0.125)\end{array}$ & $\begin{array}{l}0.012 \\
(0.024)\end{array}$ \\
\hline Mobile subscriptions & $\begin{array}{l}0.574^{* * *} \\
(0.151)\end{array}$ & $\begin{array}{l}0.574^{* * *} \\
(0.135)\end{array}$ & $\begin{array}{l}1.41^{* * *} \\
(0.115)\end{array}$ \\
\hline Constant & $\begin{array}{l}-14.07^{* * *} \\
(1.493)\end{array}$ & $\begin{array}{l}-14.07^{* * *} \\
(1.383)\end{array}$ & $\begin{array}{l}-14.019^{* * *} \\
(1.37)\end{array}$ \\
\hline
\end{tabular}

All variables are in log form

*** $1 \%$ significance level; ** $5 \%$ significance level; *10\% significance level. Standard errors are in brackets

increase in broadband penetration, GDP grows by $0.458 \%$. Although the coefficients estimated by MLE are smaller, the coefficients obtained in this case are slightly higher than that for the single-equation estimates. Again, GDP per capita has a positive and significant effect on broadband penetration. Table 6 shows the supply equation, and the GDP growth has insignificant effect on telecommunications investment. The tax rate provides positive and significant coefficients. Although this output is opposite to what might be expected naturally, that is the expected signs of these coefficients are negative as it is assumed that increase in tax rate may discourage investment. Omitted variable problem might be one of the many reasons of this result (Kennedy 2005).

The infrastructure equation shows that telecommunications investment has a positive and significant effect on the change in broadband penetration as expected. That is, for $1 \%$ increase in GDP growth, change in broadband penetration grows by $0.065 \%$. It is notable that both of the methods provide the same estimates of the coefficients, although GMM generates more efficient estimators. The full-information maximum likelihood (FIML) method has taken into account the missing values in the dataset. Comparing to the GMM method, most of the estimates by the MLE appear more efficient due to smaller standard errors. For example, in the production equation, GDP grows by an increase in broadband penetration. The more pupils were enrolled in secondary education, which has an intrinsic affirmative impact on GDP growth. Labor force is insignificant similar to the single-equation estimates. 


\begin{tabular}{|c|c|c|c|}
\hline Variables & $\begin{array}{l}3 S L S \\
\text { Coefficients and standard } \\
\text { errors }\end{array}$ & $\begin{array}{l}\text { 3SLS } \\
\text { GMM coefficients } \\
\text { and standard errors }\end{array}$ & $\begin{array}{l}\text { MLE } \\
\text { Coefficients } \\
\text { and standard } \\
\text { errors }\end{array}$ \\
\hline \multicolumn{4}{|l|}{ Investment } \\
\hline Growth & $\begin{array}{l}-0.279 \\
(0.317)\end{array}$ & $\begin{array}{l}-0.279 \\
(0.263)\end{array}$ & $\begin{array}{l}-0.344 \\
(0.351)\end{array}$ \\
\hline $\operatorname{Tax}$ & $\begin{array}{l}0.924^{* *} \\
(0.456)\end{array}$ & $\begin{array}{l}0.924^{*} \\
(0.521)\end{array}$ & $\begin{array}{l}2.117^{* * *} \\
(0.47)\end{array}$ \\
\hline Constant & $\begin{array}{l}15.002^{* * *} \\
(1.665)\end{array}$ & $\begin{array}{l}15.002^{* * *} \\
(2.09)\end{array}$ & $\begin{array}{l}11.73 \\
(1.731)\end{array}$ \\
\hline \multicolumn{4}{|l|}{$\Delta$ penetration } \\
\hline Investment & $\begin{array}{l}0.065^{* *} \\
(0.032)\end{array}$ & $\begin{array}{l}0.065^{* *} \\
(0.024)\end{array}$ & $\begin{array}{l}-0.039 \\
(0.029)\end{array}$ \\
\hline Constant & $\begin{array}{l}-0.065 \\
(0.032)\end{array}$ & $\begin{array}{l}-0.98^{*} \\
(0.47)\end{array}$ & $\begin{array}{l}1.249 \\
(0.587)\end{array}$ \\
\hline
\end{tabular}

All variables are in log form

***1\% significance level; **5\% significance level; ${ }^{*} 10 \%$ significance level. Standard errors are in brackets

The demand function shows that for $1 \%$ increase in GDP per capita and mobile cellular subscription per 100 people, broadband penetration increases by about $0.766 \%$ and $1.41 \%$, respectively. The supply function provides a positive and significant estimate of tax rate. None of the coefficients from the infrastructure equation appears significant.

With respect to significance, MLE produces outputs similar to GMM and 3SLS for the demand and production equation, whereas outputs of the supply and the infrastructure equations differ from that of the GMM and 3SLS estimates. The infrastructure equation contains no significant coefficients indicating a poor fit of the model when taking into account the full information of the whole system.

This study finds that the OLS estimation is not appropriate as it fails to solve the endogeneity problem and capture the heterogeneity of the panel data. Although the two-stage least squares method by pooled, fixed effect and random effect regression provides evidence of that broadband penetration has significant impact on economy and in turn it is highly influenced by the economic growth when considering the structural equations simultaneously, it does not take into account the covariance between the errors of the production and demand equations. Thus in order to solve the problems of endogeneity and the covariance of errors, the three-stage least square and 3SLS GMM were used to estimate the model, where GMM produces comparatively more efficient results than 3SLS and generates consistent estimates under the orthogonality conditions (Wooldridge 2010). Again, under the conditional assumption of normality, the MLE was performed to gain more efficient estimates of the coefficients. The advantage of using MLE was that it took the missing values in the account and utilized the full information in the dataset. Thus, with respect to missing values, it can be said that MLE succeeds to capture the true information provided by the data and provides an efficient estimates in the presence of the missing values. 


\section{Conclusion}

The results from the analysis suggest that broadband penetration in particular, broadband adoption contributes to the GDP growth of a country significantly, while economic growth also plays a vital role in the technological development as increasing broadband penetration encourages growth in telecommunications investment which leads to more development in this sector. A simultaneous model was estimated which includes endogeneity telecommunications infrastructure by specifying a demand and supply model. The model was estimated by both the single-equation and system equation method. By addressing the simultaneity error, both of these method show that the relationship between broadband penetration and economic growth is statistically significant. This result is consistent with the existing assumption and evidence regarding the impact of broadband on economy provided by the earlier researches. For example, Alderete (2017) found the evidence of a significant impact of broadband penetration on economic growth. Again, the important contribution of broadband usage to economic development in rural areas of the USA was explored by Prieger (2013).

The use of broadband service is greater in the countries with higher GDP, and the increasing adoption of this technology in the developing economies creates great prospects of economic thrive for these countries. The study shows that the rate of increase in broadband penetration is much slower for the South Asian countries than for countries with higher GDP outside this region, while the use of mobile phones across these countries does not show such discrimination. This indicates that developing countries are looking for technological development which can be achieved by an increasing access to as well as use of broadband. Thus for the economies with lower broadband penetration, a broadband strategy may be built nationally to promote competition in broadband investment and encourage its demand.

Acknowledgements

Not applicable.

Authors' contributions

All the authors in this research paper have their own contribution. All authors read and approved the final manuscript.

Funding

This is an original research work without any funding from extraneous sources.

Availability of data and materials

Data were collected from World Bank open source (World Development Indicator: WDI): http://datatopics.worldbank. org/world-development-indicators/.

Competing interests

The authors declare that they have no competing interests. Author's names are aligned according to their contribution.

Author details

${ }^{1}$ Institute of Statistical Research and Training (ISRT), University of Dhaka, Dhaka 1000, Bangladesh. ${ }^{2}$ Department of Development Studies, University of Dhaka, Dhaka 1000, Bangladesh.

Received: 19 December 2018 Accepted: 30 April 2019

Published online: 08 May 2019

References

Alderete MV (2017) An approach to the broadband effect on Latin American growth: a structural model. Cuad Econ 36(71):549-569

Baltagi B (2008) Econometric analysis of panel data. Wiley, New York

Gujarati DN (2009) Basic econometrics. McGraw-Hill, New York

Haller SA, Lyons S (2015) Broadband adoption and firm productivity: evidence from Irish manufacturing firms. Telecommun Policy 39(1):1-13 
Kennedy PE (2005) Oh no! I got the wrong sign! What should I do? J Econ Educ 36(1):77-92

Koutroumpis P (2009) The economic impact of broadband on growth: a simultaneous approach. Telecommun Policy 33(9):471-485

Lee SH, Levendis J, Gutierrez L (2012) Telecommunications and economic growth: an empirical analysis of sub-Saharan Africa. Appl Econ 44(4):461-469

Prieger JE (2013) The broadband digital divide and the economic benefits of mobile broadband for rural areas. Telecommun Policy 37(6):483-502

Röller LH, Waverman L (2001) Telecommunications infrastructure and economic development: a simultaneous approach. Am Econ Rev 91(4):909-923

Sridhar K, Sridhar V (2007) Telecommunications infrastructure and economic growth: evidence from developing countries. Appl Econ Int Dev 7(2):37-56

Wooldridge JM (2010) Econometric analysis of cross section and panel data. MIT Press, Cambridge

World Bank (2017) World Development Indicator, 2017. www.worldbank.org/wdi. Last Access 17 April 2018

World Internet Users and 2017 Population Stats. http://www.internetworldstats.com/stats.htm. Last Access 13 May 2018

\section{Publisher's Note}

Springer Nature remains neutral with regard to jurisdictional claims in published maps and institutional affiliations.

\section{Submit your manuscript to a SpringerOpen ${ }^{\circ}$} journal and benefit from:

- Convenient online submission

- Rigorous peer review

Open access: articles freely available online

- High visibility within the field

- Retaining the copyright to your article

Submit your next manuscript at $\boldsymbol{\Delta}$ springeropen.com 